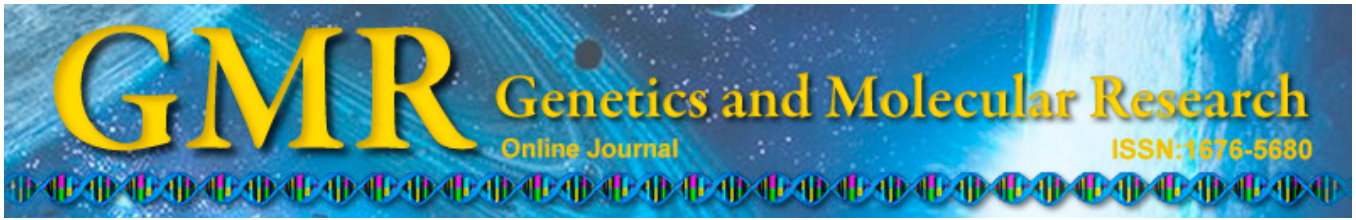

\title{
Regulating effects of insertion direction of matrix attachment regions on transgenic expression in stably transformed Chinese hamster ovary cells
}

\author{
F. Wang, J.H. Zhang, T.Y. Wang, W.H. Dong, X.J. Yang, X.Y. Wang, \\ L. Wang, R. Yang, Q. Li and C.P. Zhao \\ Department of Biochemistry and Molecular Biology, \\ Xinxiang Medical University, Xinxiang, Henan, China \\ Corresponding author: T.Y. Wang \\ E-mail: wtianyuncn@126.com
}

Genet. Mol. Res. 14 (2): 7031-7038 (2015)

Received October 10, 2014

Accepted February 26, 2015

Published June 26, 2015

DOI http://dx.doi.org/10.4238/2015.June.26.12

\begin{abstract}
We investigated the effects of different directions of insertion of matrix attachment region (MAR) sequences on transgenic expression in stably transformed Chinese hamster ovary $(\mathrm{CHO})$ cells. The MAR sequences were inserted in forward or reverse directions into the expression vectors, and transfected into $\mathrm{CHO}$ cells. The expression of the chloramphenicol acetyltransferase $(C A T)$ reporter gene and the relative copy numbers of the $C A T$ gene were analyzed. The $C A T$ gene expression levels in the vector with the MAR sequence inserted in the forward or reverse directions increased compared with expression without the MAR sequence. The relative copy numbers of the $C A T$ gene with MAR sequenced vectors inserted in the reverse and forward directions were lower, than in the control group. The direction of insertion of MAR sequences had no significant effect on expression levels. The expression levels were not proportional to the copy numbers
\end{abstract}


of the gene.

Key words: Directional effect; Matrix attachment region; Transgenic copy number; Reporter gene

\section{INTRODUCTION}

Issues about transgenic expression efficiency and stability have increased research interest in matrix attachment regions (MARs). Studies have shown that using MARs effectively addresses these transgenic expression issues. MARs are A/T-rich DNA sequences in eukaryotic chromatin with lengths ranging from 300 to $1000 \mathrm{bp}$. They, bind to the nuclear matrix (Wang et al., 2008). A number of studies have shown that the MAR sequence can be cloned into an expression vector and transformed to allow the organism to overcome transgene silencing, improve the level of transgene expression, and reduce the differences in expression among transformants (Vain et al., 1999). Studies have confirmed that the effects on transgene expression of MAR sequences from different sources are not consistent (Neznanov et al., 1996; Cheng et al., 2001; Xu et al., 2011; Xue et al., 2012; Geng et al., 2013). The $\beta$-interferon scaffold attachment region confers high-level transgene expression and avoids extinction by the epigenetic modifications of an integrated provirus in adipose tissue-derived human mesenchymal stem cells (Moreno et al., 2011).

Our previous studies have confirmed that MAR sequences can increase the transgenic expression levels of the chloramphenicol acetyltransferase (CAT) reporter gene in Chinese hamster ovary $(\mathrm{CHO})$ cells, and that heterologous MAR sequences in the sides of the expression cassette more effectively improve transgenic expression than homologous MAR sequences (Wang et al., 2012). However, few studies have investigated whether the increase in the expression level of the CAT gene caused by MAR sequences in CHO cells is related to the direction of insertion. In the present study, $5^{\prime}$ end sequences with an eukaryotic expression vector containing an expression cassette with reverse-insertion globin-MAR were constructed. The effects on transgenic expression of inserting MAR sequences into one side of the expression cassette from different directions were analyzed, and the regulatory functions of MARs were studied further.

\section{MATERIAL AND METHODS}

\section{Construction of the vector with MAR sequences inserted in the reverse direction}

Based on human $\beta$-globin MAR sequences stored in GenBank (Accession No: L22754), the primers were designed as follows: 5'-TTAGTAAGACATCACCTTGCATTT3'(forward), 5'-AGCCATAGTTTGAGTTACCCTTT-3' (reverse). To achieve directional cloning, $B g l \mathrm{II} / K p n \mathrm{I}$ restriction sites (shown in bold) (AGCGGTACC, GTCAGACTC) were designed into the $5^{\prime}$ ends of the primers. Using genomic DNA extracted from human blood as templates, the polymerase chain reaction (PCR) amplification parameters were as follows: $95^{\circ} \mathrm{C}$ for $3 \mathrm{~min} ; 94^{\circ} \mathrm{C}$ for $40 \mathrm{~s} ; 60^{\circ}-56^{\circ} \mathrm{C}$ for $40 \mathrm{~s} ; 72^{\circ} \mathrm{C}$ for $40 \mathrm{~s}, 30$ cycles; and $72^{\circ} \mathrm{C}$ for $3 \mathrm{~min}$. The PCR amplification products were analyzed by $2 \%$ agarose gel electrophoresis, recycled, ligated to the pMD-18T vector, and transformed. Positive clones were extracted, identified by electrophoresis, and sequenced.

The globin-MAR fragments connected to the T-vector were digested using $B g l \mathrm{II} / \mathrm{Kp} n \mathrm{I}$ 
restriction endonucleases. The vector pCAG (from our laboratory; Wang et al., 2010) was digested using the same enzymes. The digestion system was as follows: $10 \mu \mathrm{L}$ MAR or pCAG, $0.5 \mu \mathrm{L} \mathrm{KpnI} \mathrm{(15} \mathrm{U/ \mu L),} 0.5 \mu \mathrm{L} \mathrm{BglII}(15 \mathrm{U} / \mu \mathrm{L})$, and $2 \mu \mathrm{L} 10 \mathrm{X}$ T buffer. Afterward, $7.5 \mu \mathrm{L}$ double-distilled water was added, and the system was left in a water bath at $37^{\circ} \mathrm{C}$ for $3 \mathrm{~h}$, then analyzed by $1 \%$ agarose gel electrophoresis. The $\beta$-globin MAR fragments were recycled and the plasmid pCAG was linearized. The fragments and plasmid were then ligated and transformed. Single colonies were selected for subculturing. The plasmid was digested using restriction enzymes $K p n \mathrm{I} / B g l \mathrm{II}$ and $K p n \mathrm{I}$. The correct plasmid obtained in the digestion test was verified by means of sequencing (Figure 1). The expression vector with MAR sequences inserted in the forward direction had been constructed previously (Wang et al., 2010). All the enzymes and the pMD-18T vectors were purchased from Takara (Dalian, China).
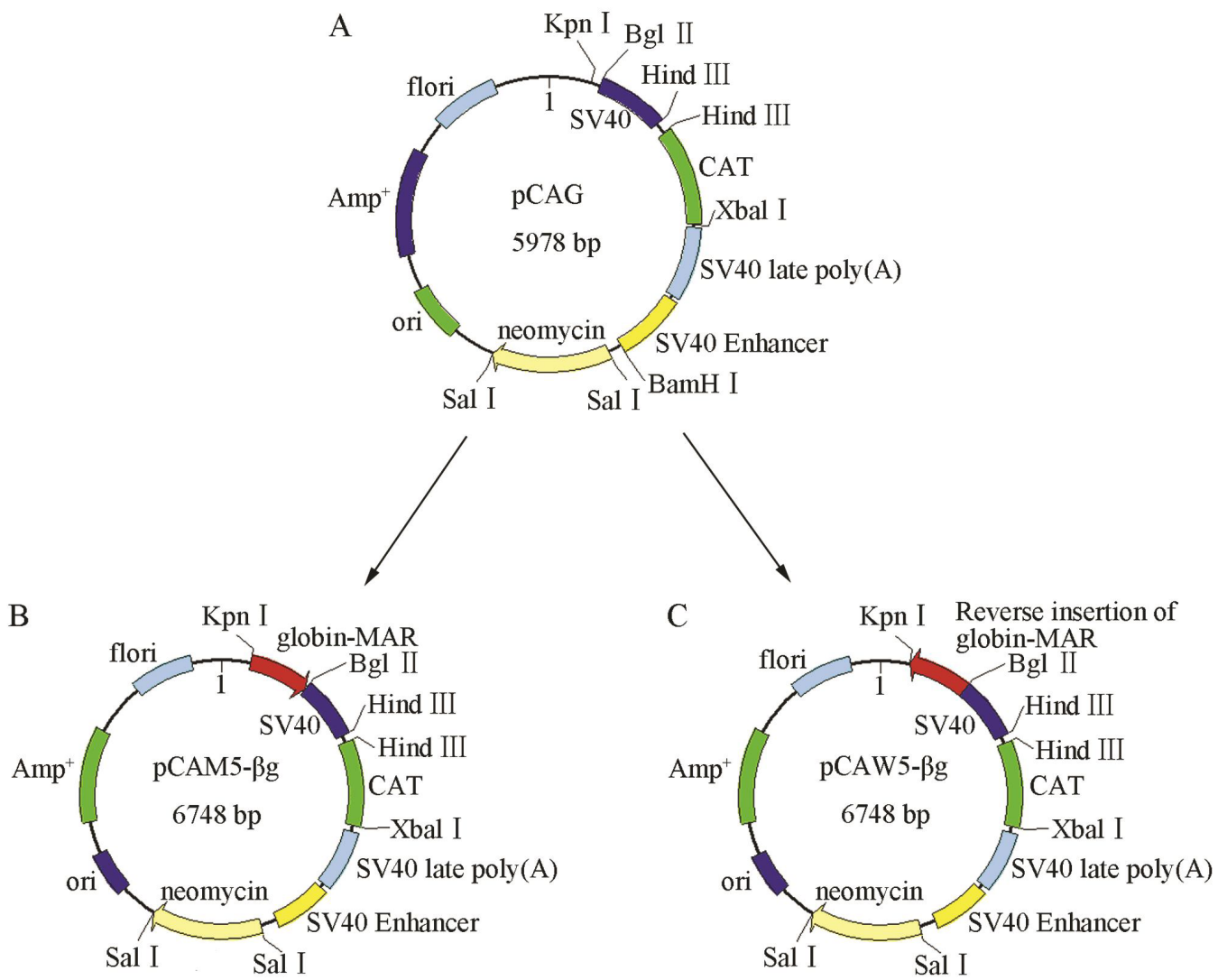

Figure 1. Vector construction A: pCAG (no MAR sequences in the expression cassette sides). B: pCCM5- $\beta \mathrm{g}$ (expression cassette $5^{\prime}$ end containing the $\beta$-globin MAR sequences inserted in the forward direction). C: pCAW5$\beta \mathrm{g}$ (expression cassette $5^{\prime}$ end containing the $\beta$-globin MAR sequence inserted in the reverse direction).

\section{Cell culture and transfection}

CHO cells (Chinese Society of Laboratory Animal Research Institute) were cultured 
using Dulbecco's modified Eagle's medium (DMEM, GIBCO, USA), which contains 10\% heat-inactivated fetal bovine serum (Sijiqing, China), $20 \mathrm{mM}$ L-glutamine, $100 \mathrm{U} / \mathrm{mL}$ penicillin, and $100 \mathrm{U} / \mathrm{mL}$ streptomycin. The cells were cultured at $37^{\circ} \mathrm{C}$ in $5 \% \mathrm{CO}_{2}$. The cells were transfected from the 24-well culture plates when cell density reached $8 \times 10^{4}-2.0 \times 10^{5}$ cells/ plate. The cells were transfected using Suohua-sofast ${ }^{\mathrm{TM}}$ (Sunmabio, Xiamen, China) reagents. The serum-free medium was removed $6 \mathrm{~h}$ after transfection and replaced with DMEM containing $10 \%$ fetal bovine serum for further incubation. This medium was replaced with 600 $\mu \mathrm{g} / \mathrm{mL}$ G418 (Sangon, Shanghai, China) in DMEM $24 \mathrm{~h}$ after transfection, then cells were selected for 2-3 weeks for screening. The transfected cells were diluted and monocloned, then distributed on 96-well culture plates for sequential culturing. The G418 concentration was decreased to $200 \mu \mathrm{g} / \mathrm{mL}$. After culturing for approximately 12 days, monoclonal colonies were collected and digested using $0.25 \%$ trypsin. The cells were then transferred to culture flasks for further analysis.

\section{CAT detection}

The cells were collected when the cell density in the culture flasks reached $1.0 \times 10^{6}$ cells $/ \mathrm{mL}$, and washed with phosphate-buffered saline. Approximately $1 \mathrm{~mL}$ lysis buffer was added to the tube in which the cell lysate was incubated at room temperature for $30 \mathrm{~min}\left(15^{\circ}\right.$ $25^{\circ} \mathrm{C}$ ). The cell lysate was centrifuged at $4^{\circ} \mathrm{C}$ and $15,000 \mathrm{~g}$ for $10 \mathrm{~min}$. The supernatant CAT enzyme levels were measured using a CAT enzyme-linked immunosorbent assay kit (Roche, Nutley, NJ, USA). The experiment was repeated three times independently.

\section{Real-time PCR}

The relative copy numbers of the $C A T$ gene were detected using real-time quantitative PCR with SYBR PCR Master Mix reagents (Beijing Kang Biotechnology, Beijing, China) and an ABI 7500 Real-Time PCR System (Applied Biosystems, Foster City, CA, USA). Genomic DNA was extracted from $2.0 \times 10^{6}$ to $5.0 \times 10^{6}$ cells using a genomic extraction kit (Beijing Kang Biotechnology, Beijing, China). The CAT gene amplification primers were designed as follows: 5'-CATCGCTCTGGAGTGAATACC-3' (forward), 5'-GGCATCAGCACCTT GTCG-3' (reverse). Primers 5'-GTCTTTCTTCTGCCGTTCTC -3' and 5'-ACCAG CCTCAT TAGGTTTGT-3' were used to amplify $\beta$-actin, which was taken as an internal reference gene. The PCR regimen was as follows: $95^{\circ} \mathrm{C}$ for $10 \mathrm{~min} ; 95^{\circ} \mathrm{C}$ for $15 \mathrm{~s}$; and $60^{\circ} \mathrm{C}$ for $1 \mathrm{~min}$, for 40 cycles. The plasmid with correct sequences was serially diluted to yield a quantitative standard amplification curve. All experiments were repeated three times. The $2^{-\Delta \Delta C T}$ method was used to analyze the relative change in gene expression levels (Livak and Schmittgen, 2001).

\section{RESULTS}

\section{Vector construction}

T-vectors ligated with globin-MAR fragments and pCAG plasmids were digested using $K p n \mathrm{I} / B g l \mathrm{II}$ restriction enzymes, and ligated with the recovered MAR fragment to the pCAG linear plasmid after digestion. The plasmids were extracted and digested using KpnI/ $B g l \mathrm{II}$ and $\mathrm{KpnI}$. The constructed plasmid had a fragment of $770 \mathrm{bp}$ cut out after $\mathrm{KpnI} / \mathrm{Bg} / \mathrm{II}$ 
digestion, and displayed a single linear DNA after digestion by a single enzyme, KpnI. The digestion results matched the construction results exactly (Figure 2), and were then delivered to the sequencing company. Correct sequences indicated that an expression vector pCAW5- $\beta \mathrm{g}$ with globin-MAR sequences inserted in a reverse direction into the $5^{\prime}$ end of the expression cassette had been successfully constructed.

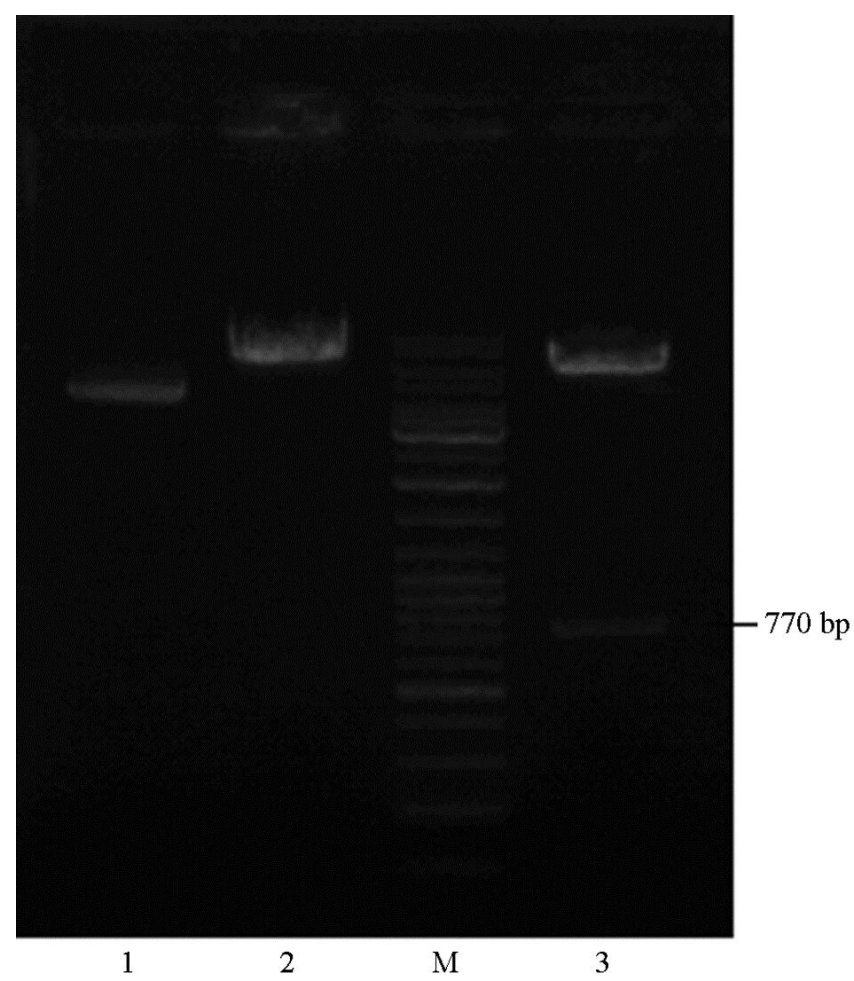

Figure 2. pCAW5- $\beta \mathrm{g}$ digestion scheme. Lane $1=$ No digested plasmid; lane $2=K p n I$ single enzyme digestion; lane $M=$ DNA marker; lane $3=K p n \mathrm{I} / B g l \mathrm{II}$ double enzyme digestion.

\section{CAT enzyme content analysis}

The CHO cells were transformed using different constructed expression vectors. A pCAG empty plasmid without MAR sequences was used as a control for the CAT activity analysis. The results of the statistical analysis of the 10 single cell clones selected showed that the expression level of the expression vector pCAW5- $\beta \mathrm{g} C A T$ gene with an expression cassette at the $5^{\prime}$ end containing globin-MAR sequences inserted in a reverse direction increased 2.1 times compared with that of the control plasmid pCAG (expression cassette at the 5 ' end without MAR sequences), and decreased by 0.9 times compared with that of the vector pCCM5- $\beta \mathrm{g}$ with an expression cassette $5^{\prime}$ end sequence inserted in a forward direction with globin-MAR. The expression level of the pCCM5- $\beta \mathrm{g} C A T$ gene increased 2.4 times compared with that of the control plasmid pCAG. Although the CAT enzyme content of the cells transformed by vector $\mathrm{pCAW5}-\beta \mathrm{g}$ and $\mathrm{pCCM} 5-\beta \mathrm{g}$ increased, unlike that of the control vector $\mathrm{pCAG}$, no significant difference was observed between the two vectors (Figure 3 and Table 1). 


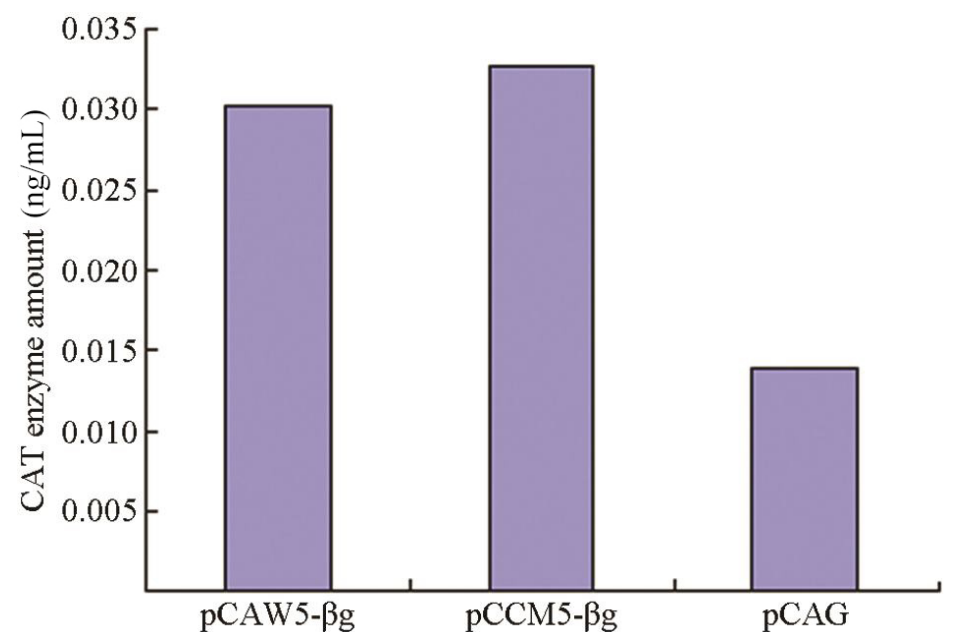

Figure 3. Effect of MAR on stable expression of the CAT gene. Average CAT enzyme content of different vector-transformed cells.

Table 1. Statistical comparison of CAT gene expressions in CHO cells transfected using different vectors.

\begin{tabular}{lccc}
\hline Statistic & pCAW5- $\beta \mathrm{g}$ & $\mathrm{pCCM} 5-\beta \mathrm{g}$ & $\mathrm{pCAG}$ \\
\hline Sample (N) & 10 & 10 & 10 \\
Mean expression & 0.03 & 0.033 & 0.014 \\
SD & 0.008 & 0.025 & 0.015 \\
CV & 0.267 & 0.756 & 1.113 \\
Fold-change & $2.1^{*}$ & $2.4^{*}$ & - \\
\hline
\end{tabular}

$* \mathrm{P}<0.01$, compared with $\mathrm{pCAG}$.

\section{Copy number analysis}

The relative copy numbers of the CAT gene in the transfected CHO cells were analyzed using real-time quantitative PCR and the $2^{-\Delta \Delta C T}$ method. The relative copy numbers of the $C A T$ gene in the CHO cells transfected by pCAW5- $\beta$ g increased 1.028 times more than those transfected by pCCM5- $\beta \mathrm{g}(\mathrm{P}<0.01)$, and decreased 0.835 times more than those of pCAG. However, the relative copy numbers of pCAW5- $\beta \mathrm{g}$ were 0.812 times lower than those of the control vector pCAG $(\mathrm{P}<0.01)$. These results indicate that the CAT protein concentrations were not directly proportional to the gene copy numbers in the CHO cells (Table 2).

Table 2. Comparison of relative gene copy numbers in $\mathrm{CHO}$ cells transfected using different vectors.

\begin{tabular}{|c|c|c|c|c|c|}
\hline & $\mathrm{C}_{\mathrm{T}}$ Mean (Vector) & $\mathrm{C}_{\mathrm{T}}$ Mean ( $\beta$-actin) & $\Delta \mathrm{C}_{\mathrm{T}}$ Mean & $\Delta \Delta \mathrm{C}_{\mathrm{T}}$ & $2^{-\Delta \Delta C T}$ \\
\hline pCAW5- $\beta \mathrm{g}$ & 30.15 & 25.90 & 4.25 & 0 & 1 \\
\hline pCCM5- $\beta \mathrm{g}$ & 30.18 & 25.89 & 4.29 & -0.04 & 1.028 \\
\hline pCAG & 27.20 & 23.21 & 3.99 & 0.26 & -0.835 \\
\hline
\end{tabular}

\section{DISCUSSION}

Given that eukaryotic mammalian cell expression systems can accomplish correct protein folding and posttranslational processing of foreign genes, they are important to genetic 
engineering. However, the expression level of foreign genes is not high because of gene silencing caused by factors such as position effects. Thus, increasing the expression level of foreign genes and overcoming gene silencing are necessary. The use of the MAR, developed in recent years, can effectively overcome exogenous gene inactivation. Many studies have focused on increasing the expression of exogenous genes using nuclear MARs (Klehr et al., 1991; Chavali et al., 2011; Harraghy et al., 2011; Jin et al., 2012; Koirala et al., 2013; Ley et al., 2013).

MAR sequences may increase the production of recombinant proteins (Harraghy et al., 2012), and $\beta$-globin MAR can improve the stable genomic expression of the Sleeping Beauty transposon (Sjeklocha et al., 2011). The development of S/MAR minicircles can enhance and assist transgene expression in the mouse liver (Argyros et al., 2011). In the present study, two constructed eukaryotic expression vectors, each with an expression cassette 5 ' end containing MAR sequences, one inserted in the forward direction and the other in the reverse direction, were used to transfect $\mathrm{CHO}$ cells. The results show that the CAT enzyme content of the cells transformed by globin-MAR sequences inserted in reverse and forward directions improved significantly compared with those of the cells transformed without MAR sequences. However, the expression levels of the CAT reporter genes of the two cells exhibited no significant differences. This effect may be due to the particular base sequences formed by the MAR fragments and the DNA bases, which are not affected by DNA direction. These findings are consistent with those of previous studies (Zahn-Zabal et al., 2001).

Studies have shown that the transgenic expression functions of MARs are unrelated to transgenic copy numbers, and the presence of MARs has no effect on transgenic copy numbers (Piechaczek et al., 1999; Li et al., 2008; Wang et al., 2010, 2012). However, some studies have suggested that the effect of MARs on transgenic expression depends on transgenic copy numbers (Kim et al., 2004; Oh et al., 2005). Our results indicate that the expression level of the MAR CAT gene inserted in the reverse direction is lower than that of the MAR inserted in the forward direction. However, the relative gene copy numbers of the reverse MAR were higher than those of the forward MAR. Thus, transgenic expression levels and gene copy numbers are not directly related to the direction of insertion of MARs.

Although numerous experiments have proven that MAR sequences can improve exogenous gene expression levels and reduce transgenic silencing, the gene expression regulation of MARs at the chromatin level and the mechanisms of transgenic expression effects are still poorly understood and require further in-depth study.

\section{Conflicts of interest}

The authors declare no conflict of interest.

\section{ACKROWLEDGMENTS}

Research supported by grants from the National Natural Science Foundation of China (\#31371332 and \#31300702).

\section{REFERENCES}

\footnotetext{
Argyros O, Wong SP, Fedonidis C, Tolmachov O, et al. (2011). Development of S/MAR minicircles for enhanced and persistent transgene expression in the mouse liver. J. Mol. Med. 89: 515-529.

Chavali PL, Funa K and Chavali S (2011). Cis-regulation of microRNA expression by scaffold/matrix-attachment regions.
} 
Nucleic Acids Res. 39: 6908-6918.

Cheng ZQ, Targolli J and Wu R (2001). Tobacco matrix attachment region sequence increased transgene expression levels in rice plants. Mol. Breeding 7: 317-327.

Geng L, Chi J, Shu C, Gresshoff PM, et al. (2013). A chimeric cry8Ea1 gene flanked by MARs efficiently controls Holotrichia parallela. Plant Cell Rep. 32: 1211-1218.

Harraghy N, Regamey A, Girod PA and Mermod N (2011). Identification of a potent MAR element from the mouse genome and assessment of its activity in stable and transient transfections. J. Biotechnol. 154: 11-20.

Harraghy N, Buceta M, Regamey A, Girod PA, et al. (2012). Using Matrix Attachment Regions to Improve Recombinant Protein Production. Methods Mol. Biol. 801: 93-110.

Jin Y, Liu Z, Cao W, Ma X, et al. (2012). Novel Functional MAR Elements of Double Minute Chromosomes in Human Ovarian Cells Capable of Enhancing Gene Expression. PLoS One 7: e30419.

Kim JM, Kim JS, Park DH, Kang HS, et al. (2004). Improved recombinant gene expression in CHO cells using matrix attachment regions. J. Biotechnol. 107: 95-105.

Klehr D, Maass K and Bode J (1991). Scaffold-attached regions from the human interferon beta domain can be used to enhance the stable expression of genes under the control of various promoters. Biochemistry 30: 1264-1270.

Koirala A, Makkia RS, Conley SM, Cooper MJ, et al. (2013). S/MAR-containing DNA nanoparticles promote persistent RPE gene expression and improvement in RPE65-associated LCA. Hum. Mol. Genet. 22: 1632-1642.

Ley D, Harraghy N, Le Fourn V, Bire S, et al. (2013). MAR Elements and Transposons for Improved Transgene Integration and Expression. PLoS One 8: e62784.

Li J, Brunner AM, Meilan R and Strauss SH (2008). Matrix attachment region elements have small and variable effects on transgene expression and stability in field-grown Populus. Plant Biotechnol. J. 6: 887-896.

Livak KJ and Schmittgen TD (2001). Analysis of relative gene expression data using real-time quantitative PCR and the 2(-Delta Delta C(T)) Method. Methods 25: 402-408.

Moreno R, Martínez I, Petriz J, Nadal M, et al. (2011). The $\beta$-interferon scaffold attachment region confers high-level transgene expression and avoids extinction by epigenetic modifications of integrated provirus in adipose tissuederived human mesenchymal stem cells. Tissue Eng. Part C Methods 17: 275-287.

Neznanov N, Kohwi-shigematsu T and Oshima RG (1996). Contrasting effects of the SATBI core nuclear matrix attachment and flanking sequences of keratin 18 gene in transgenic mice. Mol. Biol. Cell 7: 541-552.

Oh SJ, Jeong JS, Kim EH, Yi NR, et al. (2005). Matrix attachment region from the chicken lysozyme locus reduces variability in transgene expression and confers copy number-dependence in transgenic rice plants. Plant Cell Rep. 24: $145-154$

Piechaczek C, Fetzer C, Baiker A, Bode J, et al. (1999). A vector based on the SV40 origin of replication and chromosomal S/MARs replicates episomally in CHO cells. Nucleic Acids Res. 27: 426-428.

Sjeklocha L, Chen Y, Daly MC, Steer CJ, et al. (2011). $\beta$-globin matrix attachment region improves stable genomic expression of the Sleeping Beauty transposon. J. Cell Biochem. 112: 2361-2375.

Vain P, Worland B, Kohli A, Snape JW, et al. (1999). Matrix attachment regions increase transgene expression levels and stability in transgenic rice plants and their progeny. Plant J. 18: 233-242.

Wang F, Wang TY, Tang YY, Zhang JH, et al. (2012). Different matrix attachment regions flanking a transgene effectively enhance gene expression in stably transfected Chinese hamster ovary cells. Gene 500: 59-62.

Wang TY, Yang R, Qin C, Wang L, et al. (2008). Enhanced expression of transgene in CHO cells using matrix attachment region. Cell Biol. Int. 32: 1279-1283.

Wang TY, Zhang JH, Jing CQ, Yang XJ, et al. (2010). Positional effects of the matrix attachment region on transgene expression in stably transfected CHO cells. Cell Biol. Int. 34: 141-145.

Xu MY, Zhang X, Zhang L, Luo YZ, et al. (2011). Functional analysis of BnMAR element in transgenic tobacco plants. Mol. Biol. Rep. 38: 3285-3291.

Xue Z, Lv X, Song W, Wang X, et al. (2012). SIRT1 deacetylates SATB1 to facilitate MAR HS2-MAR $\varepsilon$ interaction and promote $\varepsilon$-globin expression. Nucleic Acids Res. 40: 4804-4815.

Zahn-Zabal M, Kobr M, Girod PA, Imhof M, et al. (2001). Development of stable cell lines for production or regulated expression using matrix attachment regions. J. Biotechnol. 87: 29-42. 